\title{
The Immune Reconstitution Inflammatory Syndrome After Antiretroviral Therapy Initiation in Patients With Tuberculosis: Findings From the SAPiT Trial
}

Kogieleum Naidoo, MBChB; Nonhlanhla Yende-Zuma, MSc; Nesri Padayatchi, MBChB; Kasavan Naidoo, MSc; Niraksha Jithoo, MBChB; Gonasagrie Nair, MBChB; Sheila Bamber, MBChB; Santhana Gengiah, MA; Wafaa M. El-Sadr, MD, MPH; Gerald Friedland, MD; and Salim Abdool Karim, PhD

Background: Concerns about the immune reconstitution inflammatory syndrome (IRIS) remain a barrier to antiretroviral therapy (ART) initiation during antituberculosis treatment in co-infected patients.

Objective: To assess IRIS incidence, severity, and outcomes relative to the timing of ART initiation in patients with HIVrelated tuberculosis.

Design: Randomized, open-label clinical trial. (ClinicalTrials.gov registration number: NCT00398996)

Setting: An outpatient clinic in Durban, South Africa.

Patients: 642 patients co-infected with HIV and tuberculosis.

Measurements: In a secondary analysis of the SAPiT (Starting Antiretroviral Therapy at Three Points in Tuberculosis) trial, IRIS was assessed in patients randomly assigned to initiate ART within 4 weeks of tuberculosis treatment initiation (early integrated treatment group), within 4 weeks of completion of the intensive phase of tuberculosis treatment (late integrated treatment group), or within 4 weeks after tuberculosis therapy completion (sequential treatment group). The syndrome was defined as new-onset or worsening symptoms, signs, or radiographic manifestations temporally related to treatment initiation, accompanied by a treatment response. Severity of IRIS, hospitalization, and time to resolution were monitored.

Results: Incidence of IRIS was $19.5(n=43), 7.5(n=18)$, and 8.1 ( $n=19$ ) per 100 person-years in the early integrated, late integrated, and sequential treatment groups, respectively. Among patients with a baseline $\mathrm{CD}^{+}$count less than $0.050 \times 10^{9}$ cells $/ \mathrm{L}$, IRIS incidence was 45.5, 9.7, and 19.7 per 100 person-years in the early integrated, late integrated, and sequential treatment groups, respectively. Incidence of IRIS was higher in the early integrated treatment group than in the late integrated (incidence rate ratio, $2.6[95 \% \mathrm{Cl}, 1.5$ to 4.8$] ; P<0.001$ ) or sequential (incidence rate ratio, $2.4[\mathrm{Cl}, 1.4$ to 4.4$] ; P<0.001)$ treatment groups. More severe IRIS cases occurred in the early integrated treatment group than in the other 2 groups (35\% vs. 19\%; $P=0.179$ ), and patients in the early integrated treatment group had significantly higher hospitalization rates ( $42 \%$ vs. $14 \% ; P=0.007)$ and longer time to resolution (70.5 vs. 29.0 days; $P=0.001$ ) than patients in the other 2 groups.

Limitations: It was not possible to assess IRIS in more patients in the sequential treatment group $(n=74)$ than in the late integrated $(n=50)$ and early integrated $(n=32)$ treatment groups because of loss to follow-up, withdrawal, or death within 6 months of scheduled ART initiation. This study did not assess IRIS risk in nonambulatory patients or in those with extrapulmonary and smear-negative tuberculosis.

Conclusion: Initiation of ART in early stages of tuberculosis treatment resulted in significantly higher IRIS rates, longer time to resolution, and more severe cases of IRIS requiring hospitalization. These findings are particularly relevant to patients initiating ART with a $\mathrm{CD}^{+}$count less than $0.050 \times 10^{9}$ cells/L, given the increased survival benefit of early ART initiation in this group.

Primary Funding Source: Comprehensive International Program of Research on AIDS.

Ann Intern Med. 2012;157:313-324.

www.annals.org

For author affiliations, see end of text.
$\mathrm{C}$ o-treatment of HIV and tuberculosis is associated with an increased risk for the immune reconstitution inflammatory syndrome (IRIS) $(1,2)$, overlapping adverse effects (3), potential interactions between rifampicin and antiretroviral medications (4), high pill burden, and programmatic challenges (5). Of these, IRIS, a paradoxical clinical deterioration in patients receiving effective treatment, remains the major obstacle to antiretroviral therapy (ART) initiation during tuberculosis treatment. The syndrome results from the immune system's restored ability to mount an inflammatory response after ART or after initiation of treatment for tuberculosis (6) and presents as one of two common clinical scenarios: unmasking IRIS, in which a new infection is identified after ART initiation, or paradoxical IRIS, in which clinical worsening of an infection occurs despite effective treatment $(6,7)$. Clinical effects attributable to IRIS in patients co-infected with HIV and tuberculosis range from mild, self-limiting illness, such as fever or return of cough, to more severe effects, including lymph node enlargement; recurrent, new, or deteriorating radiologic manifestations; and death (8).

Globally, an estimated 1.37 million persons were coinfected with HIV and tuberculosis in 2009 (9). Recently published data provide compelling evidence for the benefit of early ART initiation in patients with HIV and tuberculosis. Data from the SAPiT (Starting Antiretroviral Therapy at Three Points in Tuberculosis) $(10,11)$, CAMELIA (Cambodian Early Versus Late Introduction of Antiretroviral Drugs) (10-13), and ACTG (AIDS Clinical Trials Group) $5221(10-13)$ trials show substantial survival benefit with early ART initiation among patients with $\mathrm{HIV}$ and tuberculosis who have a $\mathrm{CD}^{+}{ }^{+}$count less than $0.050 \times 10^{9}$ cells $/ \mathrm{L}$, and the SAPiT and ACTG 5221 studies both showed no discernible difference in survival 


\section{Context}

In HIV-infected patients being treated for tuberculosis, initiation of antiretroviral therapy (ART) is associated with the immune reconstitution inflammatory syndrome (IRIS).

\section{Contribution}

When ART was introduced within the first 4 weeks of tuberculosis treatment of HIV-infected patients, IRIS was more frequent, was more severe, and resolved more slowly.

\section{Caution}

In HIV-infected patients with $\mathrm{CD} 4^{+}$counts less than $0.050 \times 10^{9}$ cells $/ L$ who are receiving tuberculosis therapy, the greater risk for IRIS with early ART initiation must be balanced with a previously shown decreased mortality in this population with early ART initiation.

\section{Implication}

The timing of initiation of ART during tuberculosis therapy should be individualized.

- The Editors

among patients with a $\mathrm{CD}^{+}$count of $0.050 \times 10^{9}$ cells/ $\mathrm{L}$ or greater (10-13). Previous studies in patients with HIV and tuberculosis have shown IRIS incidence rates that varied from $11 \%$ to $71.4 \%(14-17)$. Beginning ART around the start of tuberculosis treatment in patients with a baseline $\mathrm{CD}^{+}$count less than $0.050 \times 10^{9}$ cells/L has been associated with higher risk for IRIS (11-13, 16, 18-21).

Evidence for improved clinical outcomes is compelling in co-infected patients with a $\mathrm{CD}^{+}$count less than $0.050 \times$ $10^{9}$ cells/L (11-13). However, data from the SAPiT trial show that incidence of IRIS among patients with a $\mathrm{CD} 4^{+}$ count less than $0.050 \times 10^{9}$ cells/L was 4.7 times higher in patients who started ART within 4 weeks of the start of tuberculosis treatment than in patients who started ART within 4 weeks after completion of the intensive phase of tuberculosis treatment $(P=0.004)$. In addition, incidence of IRIS among patients with a $\mathrm{CD}^{+}$count of $0.050 \times 10^{9}$ cells $/ \mathrm{L}$ or greater was 2.2 times higher in the former group than in the latter group $(P=0.010)$.

Prospective data for the systematic examination of incidence, severity, risk factors, and outcome of IRIS events relative to timing of ART initiation in patients with HIV and tuberculosis are limited. The purpose of this study was to compare IRIS risks and outcomes in patients initiating ART within a month of tuberculosis treatment initiation with those of patients initiating ART later to better guide patient-level decision making about the timing of ART initiation in patients with HIV and tuberculosis.

\section{Methods}

\section{Design Overview}

The SAPiT trial was a 3-group, randomized, openlabel clinical trial in 642 patients conducted from June
2005 to July 2010. The primary outcome, which has been reported elsewhere (10), was to determine the optimal timing of ART initiation in patients co-infected with HIV and tuberculosis. In this review, we present one of the secondary objectives of the SAPiT trial: an analysis of IRIS data by trial group.

\section{Setting and Participants}

The study was conducted at the Centre for the AIDS Programme of Research in South Africa eThekwini clinic for HIV and tuberculosis, which adjoins the Prince Cyril Zulu Communicable Disease Centre, an outpatient tuberculosis facility in Durban, South Africa. Study nurses and clinicians recruited and enrolled HIV-infected patients aged 18 years or older with sputum smear-positive tuberculosis and a screening $\mathrm{CD}^{+}$count less than $0.500 \times 10^{9}$ cells/L. All patients received standard cotrimoxazole prophylaxis and antituberculosis therapy; the latter was administered in a fixed drug combination of rifampicin, isoniazid, ethambutol, and pyrazinamide for 2 months (intensive phase), followed by isoniazid and rifampicin for 4 months (continuation phase). Per South African treatment guidelines (22), patients who had had tuberculosis in the past and were being re-treated also received streptomycin during a longer intensive phase of tuberculosis treatment. The study was approved by the Biomedical Research Ethics Committee of the University of KwaZulu-Natal and the Medicines Control Council of South Africa.

\section{Randomization and Interventions}

Patients were randomly assigned to initiate ART within 4 weeks of tuberculosis treatment initiation (early integrated treatment group), within 4 weeks after completion of the intensive phase of tuberculosis treatment (late integrated treatment group), or within 4 weeks after completion of tuberculosis therapy (sequential treatment group) (Figure 1). The study statistician generated a random allocation sequence to assign patients to one of the intervention groups. Patients were randomly assigned in a 1:1:1 ratio (with the use of sealed envelopes) to one of three study groups in permuted blocks of 6 or 9 with no stratification. The standard first-line ART regimen comprised lamivudine, $300 \mathrm{mg} / \mathrm{d}$; enteric-coated didanosine, $250 \mathrm{mg} / \mathrm{d}$ (for patients weighing $<60 \mathrm{~kg}$ ) or $400 \mathrm{mg} / \mathrm{d}$ (for patients weighing $>60 \mathrm{~kg}$ ); and efavirenz, $600 \mathrm{mg} / \mathrm{d}$. Because placebos were not used in this trial, study clinicians were not blinded to treatment group allocation when they assessed possible IRIS.

\section{Outcomes and Follow-up}

Study patients were evaluated for features of suspected IRIS by using a standardized set of criteria at every study visit, regardless of group allocation. We defined IRIS as the occurrence of new-onset or worsening symptoms, signs, or radiographic features temporally related to initiation of antiretroviral or tuberculosis treatment; an increase in $\mathrm{CD}^{+}$cell count; and exclusion of confirmed tuberculosis or antiretroviral treatment failure, toxicity, nonadherence, or new 


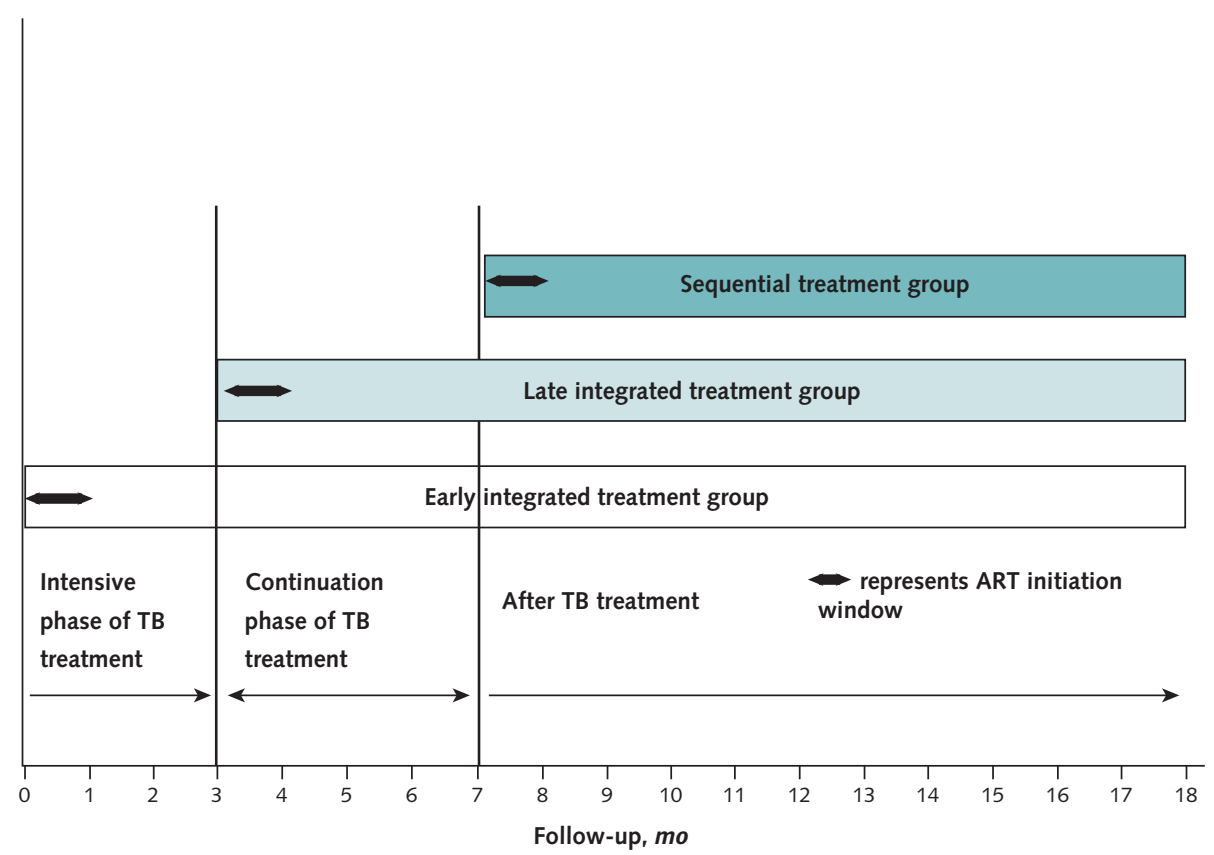

$\mathrm{ART}=$ antiretroviral therapy; SAPiT $=$ Starting Antiretroviral Therapy at Three Points in Tuberculosis; $\mathrm{TB}=$ tuberculosis.

concurrent opportunistic infection or other complication. This definition is in accordance with other published case definitions $(23,24)$ in the following respects: occurrence of IRIS after diagnosis of an underlying opportunistic infection (in this instance, tuberculosis); inclusion of an ART treatment response; presence of new-onset or worsening clinical features consistent with an inflammatory process; timing of IRIS onset relative to tuberculosis and ART initiation; and exclusion of ART and tuberculosis treatment failure, toxicity, and concurrent infections. The IRIS definition used in this study varied from published case definitions where it was not required that patients have an initial response to tuberculosis treatment or that the results of tuberculin skin tests convert from positive to negative.

Presentation of specific signs and symptoms indicative of IRIS (as per a standardized checklist) triggered a detailed IRIS assessment, which included clinical examination; urine and sputum evaluation; blood microscopy, culture, and sensitivity testing; and chest radiograph evaluation. A $\mathrm{CD}^{+}$cell count was not always measured at the time of development of IRIS symptoms; however, we used $\mathrm{CD} 4^{+}$ cell response to ART in the presence of other protocoldefining criteria of IRIS when assessing suspected IRIS. All patients presenting with clinical grade 3 and 4 IRIS events (graded according to the Table for Grading the Severity of Adult and Pediatric Adverse Events [version 1.0, December 2004], which was developed by the National Institute of Allergy and Infectious Diseases Division of AIDS) or IRIS events of a lower grade that warranted further investigation and management were referred for tertiary care to the in- fectious diseases unit at a local hospital. All cases of IRIS identified during the trial were retrospectively assessed and found to meet the 2008 International Network for the Study of HIV-Associated IRIS (INSHI) definition of 1 major clinical criterion or 2 minor clinical criteria (7). All IRIS events were followed, either until resolution or, if unresolved, until the end of study follow-up. An experienced independent clinician conducted a detailed chart review of suspected cases once all clinical and radiographic information became available to verify the IRIS diagnosis for inclusion in this analysis. We determined the severity of IRIS on the basis of IRIS-associated deaths, life-threatening events, IRIS-associated hospitalization and duration of hospitalization, number of events warranting steroid use, and proportion of IRIS events that did not resolve or resolved with sequelae at study conclusion. Every adverse event elicited by the IRIS assessment tool was graded for severity by using the Division of AIDS Table for Grading the Severity of Adult and Pediatric Adverse Events.

\section{Statistical Analysis}

The sample size for the SAPiT trial was calculated as 649, which was based on the primary mortality outcome. The study was not powered for the secondary IRIS outcome. After the second planned interim review on 1 September 2008, the study's safety monitoring committee recommended, on the basis of superior survival in the early and late integrated treatment groups, that all participants in the sequential treatment group initiate ART as soon as possible and that the 2 integrated treatment groups con- 
Original RESEARCH IRIS After ART Initiation in Patients With Tuberculosis

Table 1. Baseline Characteristics of Participants in the SAPiT Trial

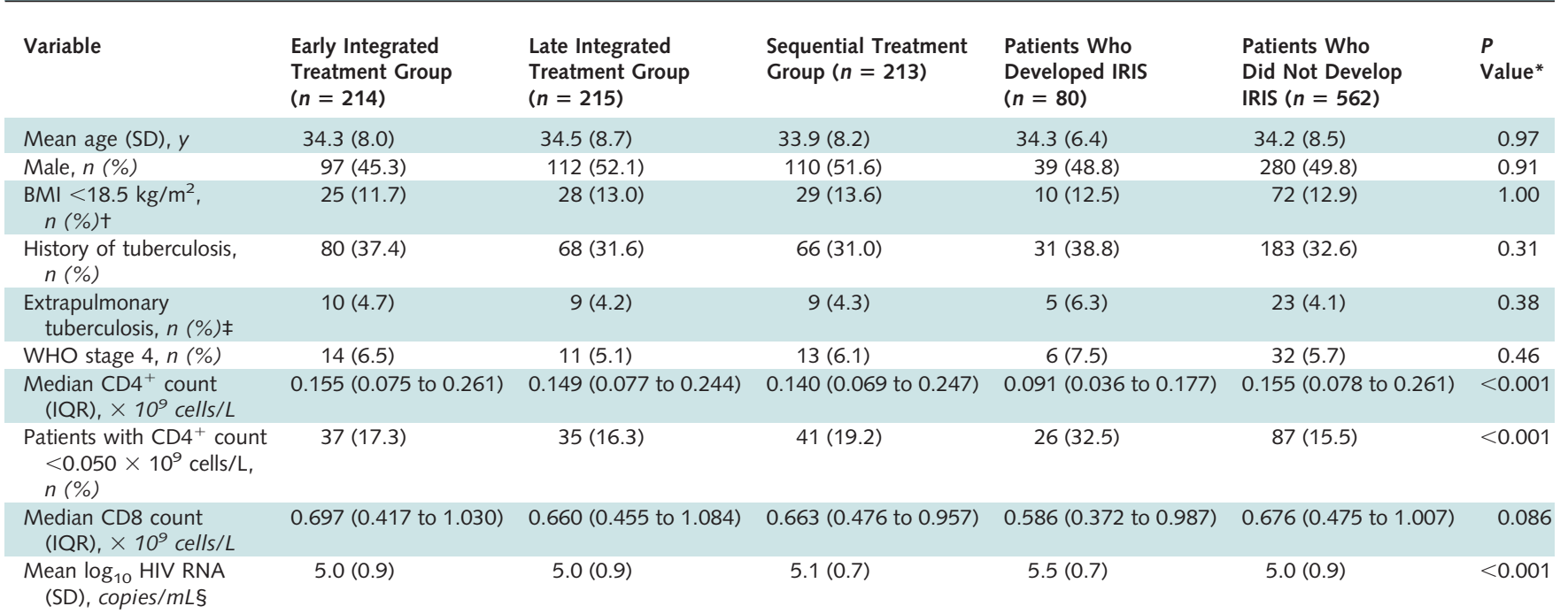

$\mathrm{BMI}=$ body mass index; IQR $=$ interquartile range; IRIS = immune reconstitution inflammatory syndrome; SAPiT $=$ Starting Antiretroviral Therapy at Three Points in Tuberculosis; $\mathrm{WHO}=$ World Health Organization.

${ }^{*} P$ value for the comparison of patients who developed IRIS with those who did not develop IRIS

† Five patients in the sequential treatment group had missing BMI data, which were not included in the percentage calculation.

₹ One patient in the late integrated treatment group and 3 patients in the sequential treatment group had missing extrapulmonary tuberculosis data, which were not included in the percentage calculation.

$\S$ Baseline viral load data were not available for 16 patients in the early integrated treatment group, 16 in the late integrated treatment group, and 12 in the sequential treatment group.

tinue follow-up with no changes. Results published in 2010 (10) provided incomplete trial data from the September 2008 safety monitoring committee review. Results presented in 2011 (11) and in this analysis were based on the complete set of trial data. We now include additional deaths, AIDS-defining illnesses, IRIS events, and follow-up data to 18 months (occurring since the safety monitoring committee's 2008 recommendation).

Statistical analyses were done by using SAS, version 9.2 (SAS Institute, Cary, North Carolina). All statistical tests were 2-sided. We calculated study duration as time from randomization to IRIS event, withdrawal from the study, death, or 18 months after randomization, whichever occurred first. Retention rate was calculated as the number of patients who completed the study, divided by the number randomly assigned, minus the number who died. We used Poisson approximations to calculate 95\% CIs for incidence rates and the $F$ test to calculate $95 \%$ CIs for the incidence rate ratios. The Fisher exact test or the FisherFreeman-Halton test was used for analysis of categorical data, and the Wilcoxon 2-sample test, 1-way analysis of variance test, or Kruskal-Wallis test was used for the analysis of continuous data. We performed sensitivity analyses to explore the effect of losses to follow-up, withdrawals, and deaths that occurred before or within 6 months after ART was initiated.

\section{Role of the Funding Source}

The funding source had no role in designing the study; collecting, analyzing, and interpreting the data; or writing the report.

\section{RESULTS}

Of 1331 patients screened for eligibility, 642 were enrolled and randomly assigned (Figure 2 ). Patients in the early integrated $(n=214)$, late integrated $(n=215)$, and sequential $(n=213)$ treatment groups had similar baseline demographic and clinical characteristics (Table 1). Retention rates (the number of patients who completed their scheduled study exit visit divided by the number of enrolled patients who did not die during follow-up) at 18 months were $76.9 \%, 71.5 \%$, and $70.9 \%$ in the early integrated, late integrated, and sequential treatment groups, respectively. Although retention rates are similar across the 3 treatment groups, we could not assess some patients for IRIS because of the timing of ART initiation in the 3 groups. Thirty-two patients in the early integrated treatment group, 50 in the late integrated treatment group, and 74 in the sequential treatment group withdrew from the study or died within 6 months after ART initiation. These 156 patients were younger overall, and most were men (Appendix Tables 1 and 2, available at www.annals.org).

\section{IRIS Incidence}

Of the 642 patients evaluated at every study visit, 85 had suspected IRIS. Five patients with pulmonary infiltrates, respiratory symptoms, thoracic lymphadenopathy, cervical lymphadenopathy, abdominal pain, and fever were subsequently found to have undiagnosed multidrugresistant tuberculosis at the time of the IRIS event and were therefore not regarded as having IRIS. Seventy-four of the remaining 80 patients with suspected IRIS had an in- 


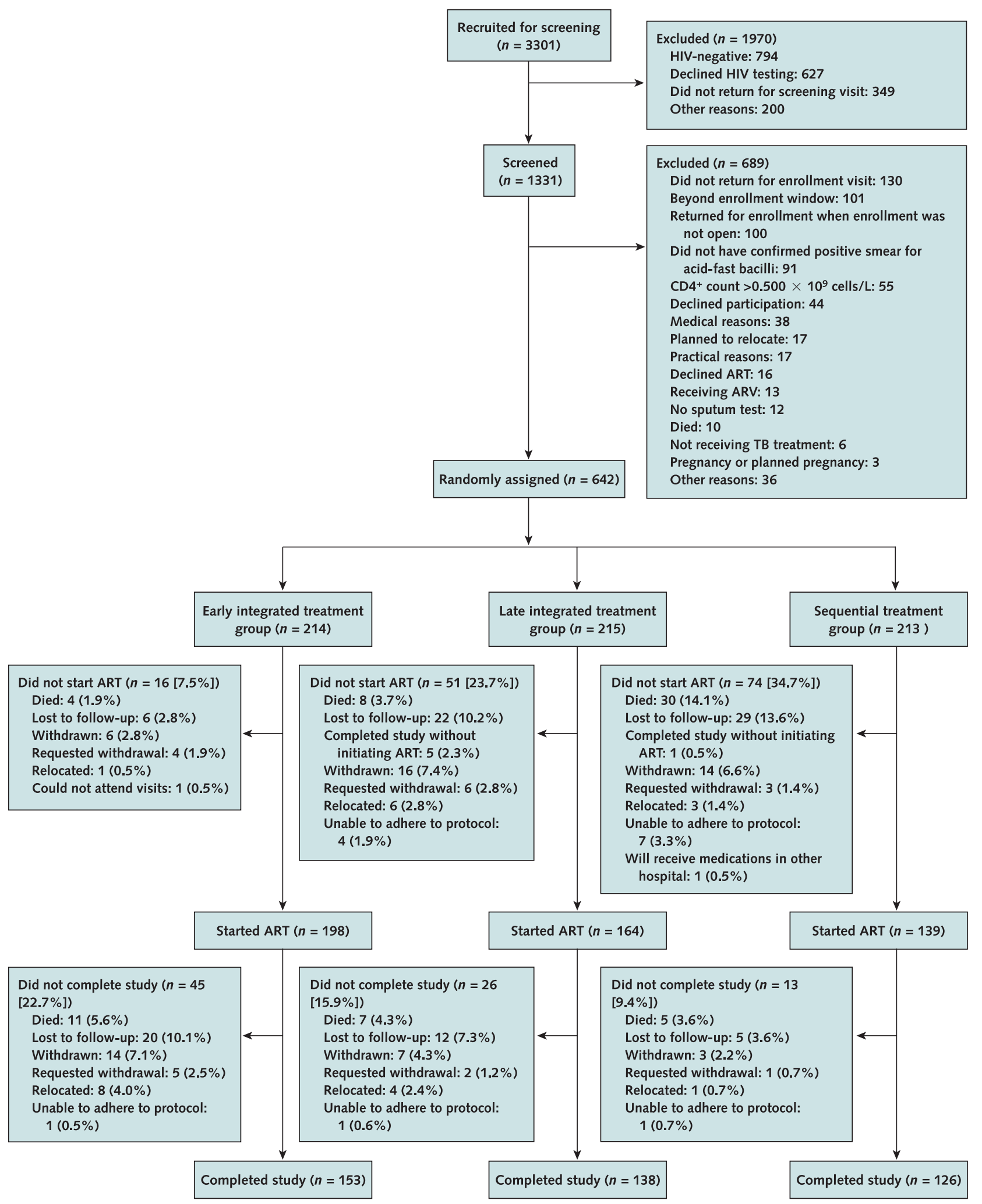

$\mathrm{ART}=$ antiretroviral therapy; $\mathrm{ARV}=$ antiretroviral drug; $\mathrm{TB}=$ tuberculosis. 
Original RESEARCH IRIS After ART Initiation in Patients With Tuberculosis

Table 2. IRIS Incidence in the SAPiT Trial, by Study Group

CD4 ${ }^{+}$Count

Early Integrated Treatment Group

\begin{tabular}{ll}
\hline IRIS & Deaths or \\
Events, & AIDS-Defining \\
$n$ & Illnesses, $n$
\end{tabular}

Person-Years*

IRIS Incidence

Rate per 100

Person-Years $(95 \% \mathrm{Cl})$

Late Integrated Treatment Group

\begin{tabular}{llll}
\hline IRIS & Deaths or & Person-Years* & IRIS Incidence \\
Events, & AIDS-Defining & & Rate per 100 \\
$n$ & Illnesses, $n$ & Person-Years \\
& & $(95 \% \mathrm{Cl})$
\end{tabular}

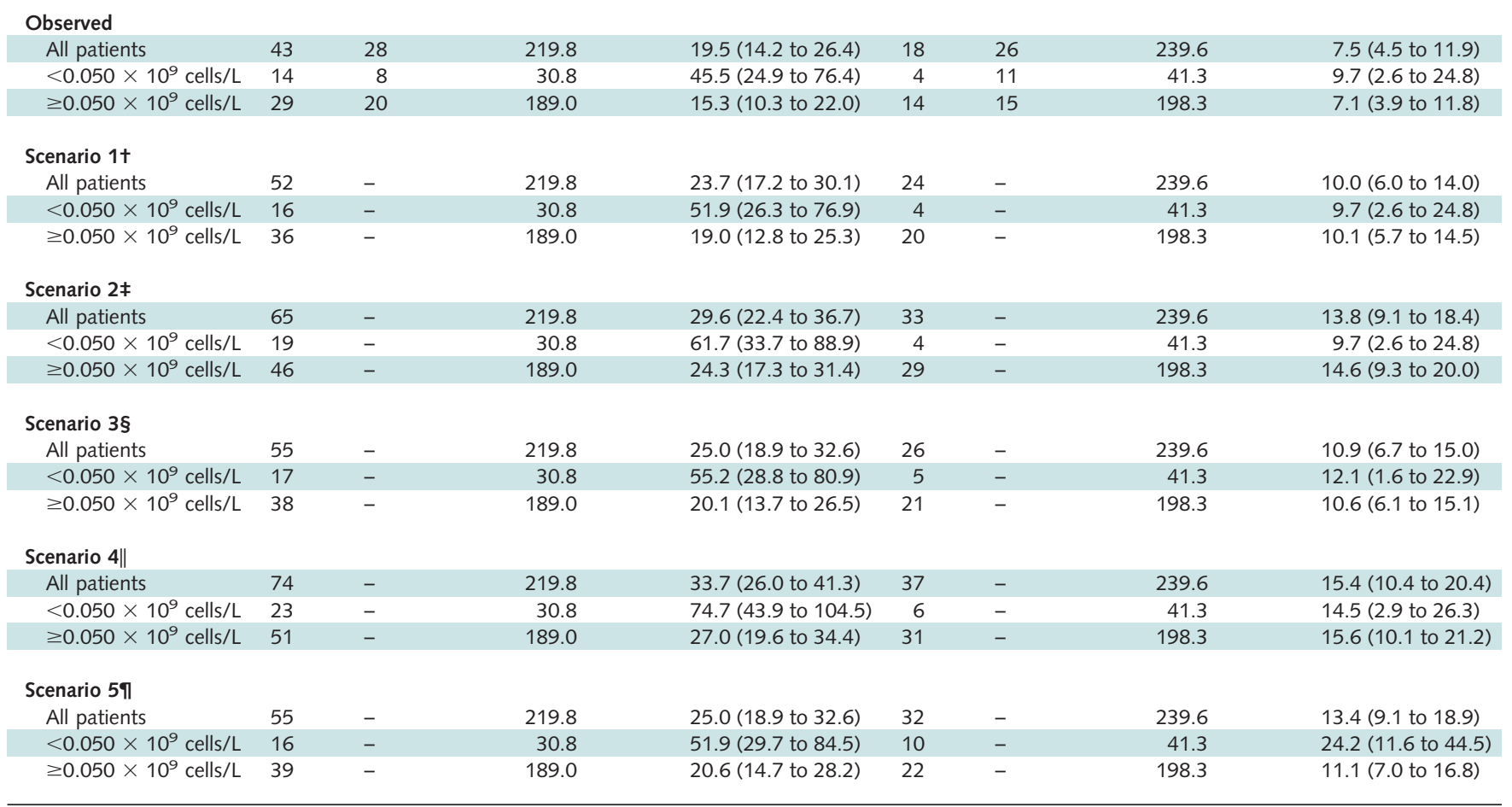

IRIS = immune reconstitution inflammatory syndrome; SAPiT = Starting Antiretroviral Therapy at Three Points in Tuberculosis.

* Data are different from those reported previously (11) because of changes in the calendar time used for censoring.

† Assumes patients who withdrew before initiation of antiretroviral therapy and within 6 mo after initiation of antiretroviral therapy had IRIS rates 2 times those of patients who did not withdraw.

¥ Assumes patients who withdrew before initiation of antiretroviral therapy and within 6 mo after initiation of antiretroviral therapy had IRIS rates 5 times those of patients who did not withdraw.

§ Assumes patients who withdrew or died before initiation of antiretroviral therapy and within 6 mo after initiation of antiretroviral therapy had IRIS rates 2 times those of patients who completed the study.

$\|$ Assumes patients who withdrew or died before initiation of antiretroviral therapy and within 6 mo after initiation of antiretroviral therapy had IRIS rates 5 times those of patients who completed the study.

ๆ Composite end point of death or IRIS.

creased $\mathrm{CD}^{+}$cell count. The remaining 6 patients $(5$ in the early integrated treatment group and 1 in the late integrated treatment group) did not have available $\mathrm{CD}^{+}$ cell count data at or after the IRIS diagnosis. Because their exclusion did not materially change the results, we included these 6 patients in the analysis.

There were 43 patients with IRIS in the early integrated treatment group, 18 in the late integrated treatment group, and 19 in the sequential treatment group (Table 2). Incidence of IRIS was significantly higher in the early integrated treatment group (19.5 per 100 person-years) than in the late integrated (7.5 per 100 person-years; $P<$ 0.001 ) or sequential (8.1 per 100 person-years; $P<0.001$ ) treatment groups (Table 2). The median number of days to IRIS from ART initiation was 17.5 in the early integrated treatment group, 17 in the late integrated treatment group, and 28 in the sequential treatment group $(P=$
0.32) (Figure 3). The median $\mathrm{CD}^{+}$count at or near the IRIS event was $0.101 \times 10^{9}$ cells/ $\mathrm{L}$ in the early integrated treatment group, $0.117 \times 10^{9}$ cells $/ \mathrm{L}$ in the late integrated treatment group, and $0.132 \times 10^{9} \mathrm{cells} / \mathrm{L}$ in the sequential treatment group $(P=0.52)$. Our results hold even if the 6 patients who did not have a $\mathrm{CD}^{+}$cell count at or after the diagnosis of IRIS are excluded from the analysis (Appendix Table 3, available at www.annals.org).

Incidence of IRIS in the subset of patients enrolled with a $\mathrm{CD}^{+}$count less than $0.050 \times 10^{9}$ cells $/ \mathrm{L}$ was 45.5 per 100 person-years in the early integrated treatment group, 9.7 per 100 person-years in the late integrated treatment group, and 19.7 per 100 person-years in the sequential treatment group $(P=0.008)$ (Table 2$)$. Incidence of IRIS in patients with a $\mathrm{CD}^{+}$count less than $0.050 \times 10^{9}$ cells/L was higher in the early integrated treatment group than in the late integrated $(P=0.004)$ or sequential $(P=$ 
IRIS After ART Initiation in Patients With Tuberculosis ORIGINAL RESEARCH

Table 2-Continued

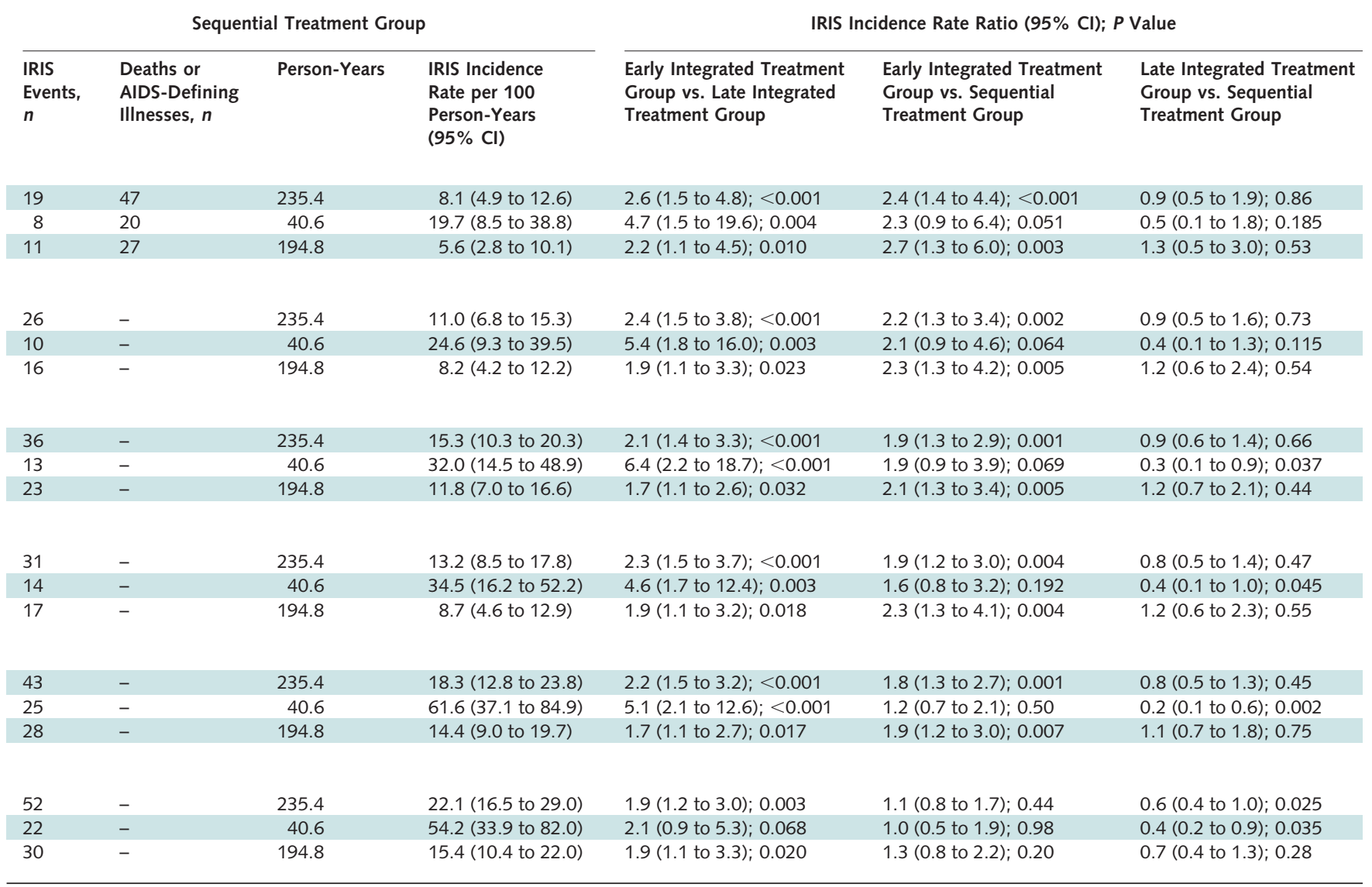

$0.051)$ treatment groups. By comparison, in patients with a $\mathrm{CD}^{+}$count of $0.050 \times 10^{9}$ cells/L or greater, incidence of IRIS was 15.3 per 100 person-years in the early integrated treatment group, 7.1 per 100 person-years in the late integrated treatment group, and 5.6 per 100 personyears in the sequential treatment group $(P=0.002)$. The incidence rate in patients enrolled with a $\mathrm{CD} 4^{+}$count of $0.050 \times 10^{9}$ cells/L or greater was significantly higher in the early integrated treatment group than in the late integrated $(P=0.010)$ or sequential $(P=0.003)$ treatment groups (Table 2). Overall, in patients with a $\mathrm{CD}^{+}$count less than $0.050 \times 10^{9}$ cells/L, the median time to IRIS from ART initiation was double that of patients with a $\mathrm{CD}^{+}$count of $0.050 \times 10^{9}$ cells/L or greater $(28$ days [interquartile range $\{\mathrm{IQR}\}, 15$ to 56 days] vs. 14 days [IQR, 13 to 28 days]; $P=0.009)$. The combination of treatment group and $\mathrm{CD}^{+}$cell count status (greater than or less than $0.050 \times 10^{9}$ cells/L) did not have a statistically significant effect on the risk for IRIS $(P=$ 0.97), indicating homogeneity across the $2 \mathrm{CD}^{+}$cell count strata in the effect of time to ART initiation on the risk for IRIS. Results from various sensitivity analyses, which assumed that patients who were lost to follow-up, withdrew, or died within 6 months after their scheduled
ART initiation had IRIS rates 2 or 5 times those observed in patients who completed follow-up, were consistent with the primary results. In a sensitivity analysis that used the composite end point of death or IRIS, outcome rates were higher in the early integrated treatment group than in the late integrated treatment group (Table 2).

New-onset or worsening respiratory symptoms (59 of 80) was the most common clinical presentation of IRIS (Figure 4). Fever was uncommon (2 of 80 ), whereas $22.5 \%$ (18 of 80) of patients with IRIS presented with new-onset or worsening lymphadenopathy. In the sequential treatment group, 2 participants who had completed tuberculosis treatment when ART was initiated developed active tuberculosis within 3 months of ART initiation and met the provisional INSHI case definition of unmasking tuberculosis-associated IRIS.

\section{Severity of IRIS Events}

Severe or life-threatening IRIS events occurred in $35 \%, 22 \%$, and $16 \%$ of patients with IRIS in the early integrated, late integrated, and sequential treatment groups, respectively (Table 3). Forty-two percent of patients with IRIS in the early integrated treatment group were hospitalized for IRIS-related conditions, compared with $22 \%$ in 


\section{Figure 3. Kaplan-Meier estimates of cumulative probability of IRIS, by study group.}

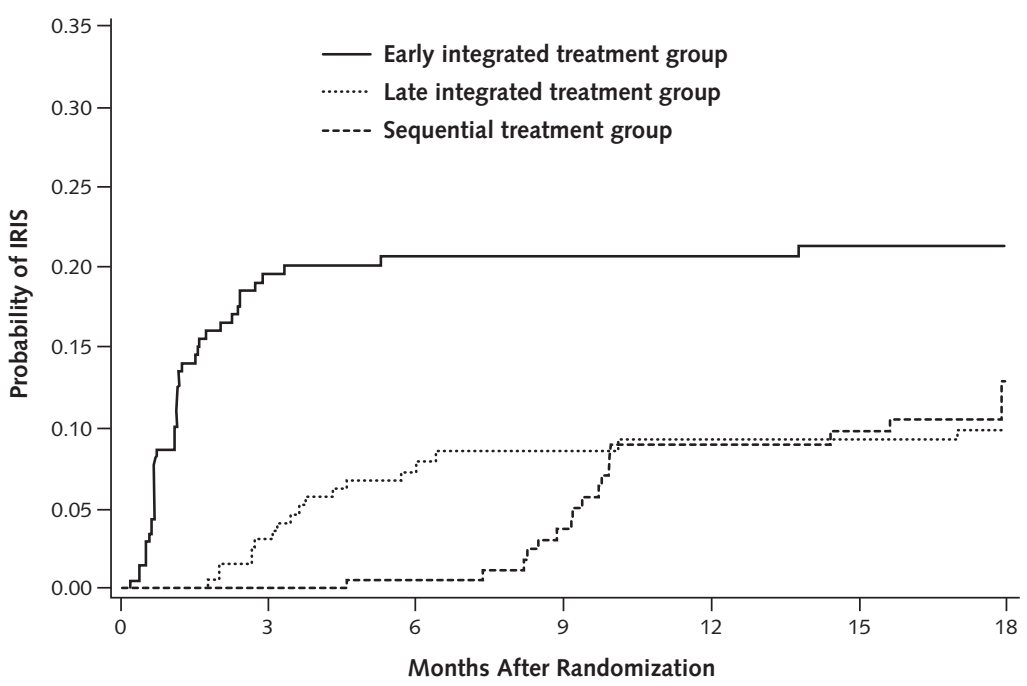

$\begin{array}{lccccccc}\begin{array}{l}\text { IRIS Events/Patients in Follow-up (Deaths; Withdrawals) } \\ \begin{array}{l}\text { Early integrated } \\ \text { treatment }\end{array}\end{array} & 214 & 40 / 156 & 42 / 145 & 42 / 141 & 42 / 138 & 43 / 131 & 43 / 121 \\ & & (4 ; 14) & (7 ; 20) & (8 ; 23) & (9 ; 25) & (9 ; 31) & (12 ; 38) \\ \begin{array}{l}\text { Late integrated } \\ \text { treatment }\end{array} & 215 & 6 / 188 & 14 / 167 & 16 / 153 & 17 / 143 & 17 / 139 & 18 / 128 \\ & & (1 ; 20) & (5 ; 29) & (9 ; 37) & (11 ; 44) & (12 ; 47) & (14 ; 55) \\ \begin{array}{l}\text { Sequential } \\ \text { treatment }\end{array} & 213 & 0 / 196 & 1 / 179 & 6 / 152 & 14 / 130 & 15 / 121 & 19 / 110 \\ & & (3 ; 14) & (12 ; 21) & (20 ; 35) & (31 ; 38) & (32 ; 45) & (33 ; 51)\end{array}$

IRIS = immune reconstitution inflammatory syndrome.

the late integrated treatment group and $5.0 \%$ in the sequential treatment group $(P=0.009)$. A total of $35 \%(15$ of 43) of IRIS cases in the early integrated treatment group were severe, compared with $19 \%$ (7 of 37) of IRIS cases in the other 2 treatment groups $(P=0.179)$. Median duration of IRIS-associated hospitalization was 9.5 days (IQR, 3 to 20 days) and 11.5 days (IQR, 6 to 23 days) in the early integrated and late integrated treatment groups, respectively. In the sequential treatment group, only $1 \mathrm{pa}-$ tient was hospitalized for 60 days. Steroid therapy was started in 8 patients with IRIS ( 4 in the early integrated treatment group, 1 in the late integrated treatment group, and 3 in the sequential treatment group). Baseline $\mathrm{CD} 4^{+}$ cell count status (greater than or less than $0.050 \times 10^{9}$ cells/L) did not affect the number of unscheduled medical visits that were due to IRIS. Seventy-two of the 80 patients with IRIS had unscheduled medical visits (median, 3 visits; range, 1 to 12 visits), whereas 351 of 562 patients without IRIS had unscheduled medical visits (median, 2 visits; range, 1 to 18 visits). Eighty of the 113 patients with a $\mathrm{CD}^{+}{ }^{+}$count less than $0.050 \times 10^{9}$ cells/L had unscheduled medical visits (median, 2 visits; range, 1 to 16 visits), whereas 343 of 529 patients with a $\mathrm{CD}^{+}$count of $0.050 \times 10^{9}$ cells $/ \mathrm{L}$ or greater had unscheduled medical visits (median, 2 visits; range, 1 to 18 visits). There was no statistically significant difference in the rate of single drug switching $(P=0.54)$ or whole regimen change due to virologic failure $(P=0.21)$ between patients with IRIS and those without it.

Seventy-two of the 80 IRIS events resolved completely during follow-up. Time to IRIS resolution was longer in the early integrated treatment group than in the late integrated and sequential treatment groups $(P=0.001)$ (Table 3). Among the unresolved IRIS events, there were 2 deaths (both in the early integrated treatment group) due to respiratory complications. Two events did not resolve by study completion (new onset of pulmonary infiltrates in the early integrated treatment group and worsening papular pruritic eruption in the sequential treatment group), and 3 IRIS events resolved with sequelae (tuberculosis meningitis and meningitis, both in the early integrated treatment group, and herpes zoster in the sequential treatment group). The outcome of IRIS in 1 patient was unknown.

\section{Risk Factors Associated With IRIS}

$\mathrm{CD}^{+}$cell count, viral load, and World Health Organization clinical disease stage were associated with an increased risk for IRIS. Incidence of IRIS was 23.1 per 100 person-years in patients with a $\mathrm{CD}^{+}$count less than 
$0.050 \times 10^{9}$ cells $/ \mathrm{L}(95 \% \mathrm{CI}, 15.1$ to 33.8 per 100 person-years), 12.3 per 100 person-years in patients with a $\mathrm{CD}^{+}{ }^{+}$count between 0.050 and $0.200 \times 10^{9}$ cells/L $(\mathrm{CI}$, 8.7 to 16.8 per 100 person-years), and 5.6 per 100 personyears in patients with a $\mathrm{CD}^{+}$count greater than $0.200 \times 10^{9}$ cells $/ \mathrm{L}$ (CI, 3.2 to 9.4 per 100 person-years). Similarly, IRIS incidence was higher in patients with a baseline viral load greater than 100000 copies $/ \mathrm{mL}(16.2$ per 100 person-years [CI, 12.4 to 20.8 per 100 personyears]) than in those with a baseline viral load less than 100000 copies/mL (6.0 per 100 person-years [CI, 3.4 to 9.7 per 100 person-years]) (Appendix Table 4, available at www.annals.org).

\section{DISCUSSION}

Patients with HIV and tuberculosis who started ART in the first 4 weeks of tuberculosis treatment had a more than 2-fold higher rate of IRIS incidence than those who started ART later. Of note, IRIS occurring in patients who initiated ART early was more severe, took longer to resolve, and more often required hospitalization.

Higher IRIS rates in patients who start ART during the early stages of tuberculosis treatment have been shown in clinical trials (11-13) and in retrospective and observational studies $(1,25-27)$. In the CAMELIA study, IRIS incidence rates were 3.76 per 100 person-months in the early initiation group versus 1.53 per 100 person-months in the late initiation group (12). Another large multicenter trial (ACTG 5221) reported IRIS rates of $11 \%$ in patients with immediate ART versus $5 \%$ in patients with early
ART (13), with $11.5 \%$ of patients with a $\mathrm{CD}^{+}$count less than $0.050 \times 10^{9}$ cells/L and $5.4 \%$ of patients with a $\mathrm{CD}^{+}$count of $0.050 \times 10^{9}$ cells/L or greater developing IRIS. This study also showed a substantial interaction between $\mathrm{CD}^{+}$cell count and ART group $(P=0.014)$. Time to IRIS from ART initiation was similar in the ACTG 5221 and SAPiT studies. The most common clinical presentation of IRIS in the ACTG 5221 study was lymphadenopathy followed by new-onset constitutional symptoms, whereas fever followed by peripheral lymphadenopathy was the most common clinical presentation of IRIS in the CAMELIA study. In contrast, new-onset or worsening respiratory symptoms followed by pulmonary infiltrates was the most common clinical presentation of IRIS in the SAPiT trial. These different presentations of IRIS are probably due to the different patient profiles in the 3 studies-patients in the SAPiT trial were all ambulatory and had smear-positive tuberculosis, patients in the ACTG 5221 trial were a mix of ambulatory and hospitalized patients with all forms of tuberculosis, and most patients in the CAMELIA trial were hospitalized with a clinically significantly lower baseline $\mathrm{CD}^{+}$cell count than patients in the other 2 trials.

Our study also shows that in severely immunocompromised patients $\left(\mathrm{CD}^{+}\right.$count $<0.050 \times 10^{9}$ cells/L), risk for IRIS was almost 5 times higher in those initiating ART early. It is important to note that within this population, studies have shown a substantial decrease in the risk for morbidity and mortality with early ART initiation (1113). Patients with a $\mathrm{CD}^{+}{ }^{+}$count of $0.050 \times 10^{9}$ cells $/ \mathrm{L}$ or

Figure 4. Proportion of all patients with IRIS who developed clinical signs, symptoms, and radiographic features of IRIS.

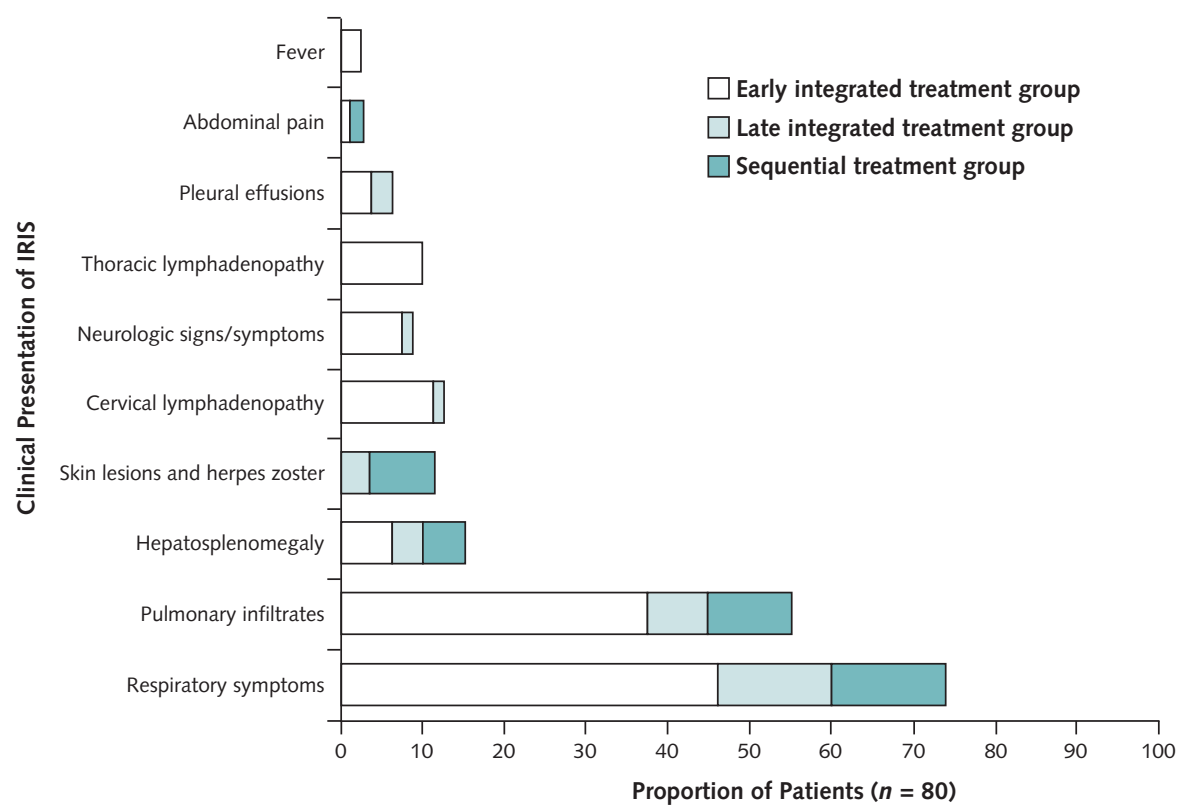

IRIS = immune reconstitution inflammatory syndrome. 
Table 3. IRIS Severity, by Study Group

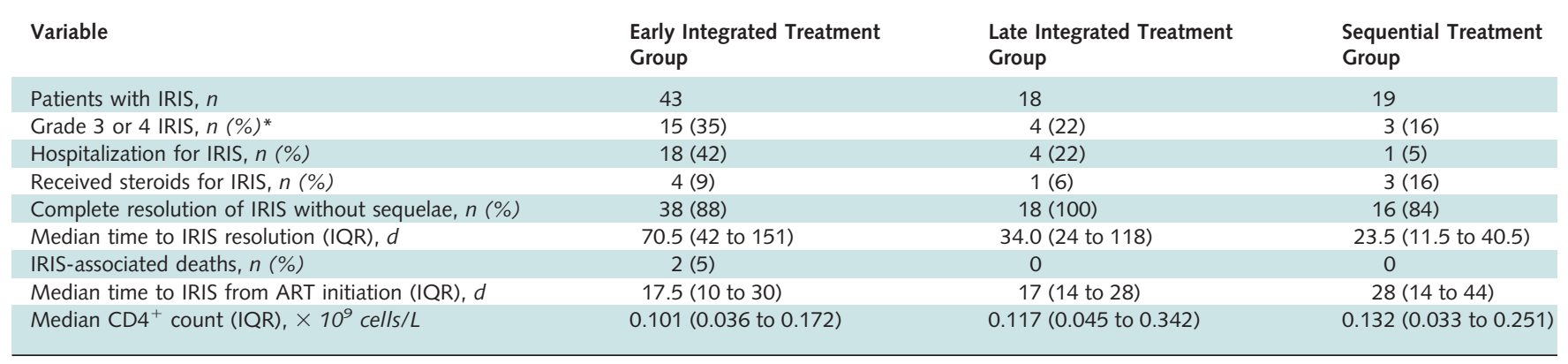

$\mathrm{ART}=$ antiretroviral therapy; IQR $=$ interquartile range; IRIS = immune reconstitution inflammatory syndrome.

* Severity of IRIS events was graded by using the Table for Grading the Severity of Adult and Pediatric Adverse Events (version 1.0, December 2004), developed by the National Institute of Allergy and Infectious Diseases Division of AIDS.

greater did not gain a survival benefit from ART initiation within the first 4 weeks compared with ART initiation at the start of the continuation phase of tuberculosis treatment, but they had a 2-fold higher risk for IRIS (15.3 vs. 7.1 per 100 person-years) (11). Similarly, no discernible survival or decreased morbidity benefit was evident with early ART initiation in patients with a $\mathrm{CD}^{+}$count of $0.050 \times 10^{9}$ cells/L or greater in the ACTG 5221 study; the incidence rate of AIDS or death was $11.5 \%$ in patients who initiated ART within 2 weeks compared with $10.3 \%$ in those initiating ART within 8 to 12 weeks of the start of tuberculosis treatment (13).

In addition to being more common, IRIS was more severe in patients initiating ART in the first 4 weeks of tuberculosis treatment. Those who initiated ART early had greater burden of IRIS-related illness, longer duration of illness, more steroid use, and higher rates of hospitalization. Two thirds of all severe or life-threatening IRISassociated adverse events occurred in patients in the early integrated treatment group. These patients had a disproportionately high number (approximately $80 \%$ ) of the IRIS-associated hospitalizations in the study. Consistent with previously published data $(14,20,26,28)$, low baseline $\mathrm{CD}^{+}$cell count and high baseline viral load were statistically significant risk factors for IRIS in our study. Time to IRIS resolution in the early integrated treatment group was 2-fold higher than that in the late integrated treatment group and 3-fold higher than that in the sequential treatment group. Furthermore, 50\% of all patients requiring steroids for management of IRIS were in the early integrated treatment group. Steroid therapy was prescribed in $10 \%$ of patients with IRIS in this study to alleviate the clinical course of IRIS when life-threatening, space-occupying lesions or danger of respiratory failure existed. However, the role of corticosteroids in management of IRIS has not been clearly defined. A study has shown that steroids reduced the need for hospitalization and therapeutic procedures and hastened improvement in IRIS symptoms, whereas other studies caution against steroids in patients with IRIS because they have been shown to exac- erbate underlying opportunistic infections, including drugresistant tuberculosis and Kaposi sarcoma $(29,30)$. There was no difference in the number of unscheduled medical visits or drug switching due to toxicity or virologic failure between patients who developed IRIS and those who did not develop IRIS. It is important to underscore that, overall, we found that the IRIS-associated death rate was relatively low and that IRIS had a relatively benign nature. These findings are clinically relevant on 2 levels: For individual patients, they increase confidence in coadministering tuberculosis and HIV treatment without fear of worsening morbidity and mortality due to IRIS; for public health, they indicate that tuberculosis and HIV integration can occur without increasing the availability of resources for IRIS management, especially in settings where tuberculosis and HIV are endemic.

In light of higher IRIS-associated morbidity with early ART in tuberculosis treatment, the decision on the timing of ART in co-infected patients should be influenced by baseline $\mathrm{CD}^{+}$cell counts because of the association between risk for IRIS and reported morbidity and mortality benefit by $\mathrm{CD}^{+}$cell count strata. Thus, in patients with a $\mathrm{CD}^{+}$count less than $0.050 \times 10^{9}$ cells $/ \mathrm{L}$, the balance of benefit and risk would favor initiation of ART within 4 weeks of tuberculosis treatment initiation. On the other hand, in patients with a $\mathrm{CD}^{+}$count of $0.050 \times 10^{9}$ cells/L or greater, the decision of early versus later initiation of ART during tuberculosis treatment must be weighed against the availability of clinical capacity to diagnose and manage IRIS. Hence, careful consideration is required to assess the potential benefits and risks of each strategy in each clinical setting. Of note, in patients with a $\mathrm{CD}^{+}$count greater than $0.050 \times 10^{9}$ cells/L, although ART initiation may be deferred for 8 to 12 weeks after tuberculosis treatment initiation, every effort should be made to initiate ART no later than 12 weeks after tuberculosis treatment initiation. In addition, early initiation of ART should be strongly considered among patients with a $\mathrm{CD}^{+}$count greater than $0.050 \times 10^{9}$ cells $/ \mathrm{L}$ who also have a clinical disease of major severity; organ system dys- 
function; or low Karnofsky performance score, body mass index, hemoglobin level, or albumin level, because these variables are associated with higher mortality rates.

Our study has several limitations. First, because we enrolled ambulatory patients with sputum smear-positive tuberculosis, our results may not be directly generalizable to all forms and severities of tuberculosis in HIV-infected patients. Although the difference in patient retention across the 3 study groups was not statistically significant, it is possible, albeit unlikely, that ascertainment of IRIS was greater in the early integrated treatment group than in the other 2 groups as a result of more patients being retained in that group. In addition, we were unable to assess IRIS in patients who were lost to follow-up, withdrew, or died before or 6 months after their scheduled ART initiation, but results comparing early and late integrated treatments were unchanged in various sensitivity analyses.

Second, in the absence of placebo use in this trial, study clinicians knew when a patient began ART, which could have biased the assessment of whether IRIS was present. We mitigated this bias to some extent by using standard checklists that were followed for clinical assessments and diagnosis of IRIS. It was not possible to prevent treating clinicians from knowing when patients initiated ART, and this may have affected their clinical management decisions, including whether to hospitalize. We attempted to minimize this limitation by a standard procedure that required a second clinician to give an opinion on hospitalization. Decisions on steroid use were made by hospital clinicians unrelated to the study.

Further studies may be necessary to assess IRIS risk in nonambulatory patients and in those with extrapulmonary and smear-negative tuberculosis. Although $\mathrm{CD}^{+}{ }^{+}$cell count was a strong prognostic indicator of IRIS risk, $\mathrm{CD}^{+}$cell count assays are not always available in many settings. Decisions on the timing of ART in individual patients need to be modified by clinical judgment of disease severity and consideration of capacity to diagnose and manage IRIS. In the absence of a reliable diagnostic test for IRIS, it is possible that misclassification bias occurred. Milder forms of IRIS were probably missed because IRIS diagnosis is dependent on patient self-reporting of specific symptoms and clinician awareness, especially where diagnostic radiography is not routinely available or is inaccessible, even to symptomatic patients. This issue was addressed procedurally through use of a standardized IRIS evaluation checklist, which was administered to every patient at each clinical visit. The INSHI criteria for IRIS diagnosis were published 3 years after we commenced our study (7). Despite the lack of a standardized case definition for IRIS at the time, we implemented several steps in the design and conduct of the study to ensure consistency in reporting, recording, and interpreting suspected IRIS.

We address an important and current topic in the management of individuals co-infected with HIV and tuberculosis by using data from a randomized clinical trial that had more cases of IRIS (80 patients) than prior reports and used a single ART regimen in a well-characterized, smear-positive tuberculosis cohort. Because integration of tuberculosis and HIV treatment can reduce mortality by $56 \%$ (10), decisions on when to start ART during tuberculosis treatment should take into account the balance of risk and severity of IRIS and potential benefit in relation to morbidity or mortality. Incidence of IRIS is substantially higher in patients starting ART earlier after tuberculosis treatment initiation. Although patients with severe immunosuppression have a clear survival benefit from early ART initiation despite high IRIS risk (11-13), this balance of risks and benefits is different in patients with a higher $\mathrm{CD}^{+}$cell count. Deferring ART initiation by as much as 12 weeks after tuberculosis treatment initiation may be an appropriate strategy in stable ambulatory patients with a $\mathrm{CD} 4^{+}$count of $0.050 \times 10^{9}$ cells/ $\mathrm{L}$ or greater because this approach offers lower incidence and severity of IRIS without increasing the risk for AIDS or death. Future research efforts need to focus on finding a reliable diagnostic marker of IRIS in routine clinical and laboratory settings. Furthermore, a randomized, placebo-controlled trial that would investigate whether corticosteroids in patients with a $\mathrm{CD}^{+}{ }^{+}$count less than $0.050 \times 10^{9}$ cells/ $\mathrm{L}$ initiating highly active ART early in tuberculosis treatment reduce frequency and severity of IRIS events and need for hospitalization is warranted. In addition, validated clinical and laboratory tools to reliably diagnose IRIS will simplify clinical management decisions for patients with HIV and tuberculosis.

From University of KwaZulu-Natal and eThekwini Research Clinic, Durban, South Africa; Columbia University, New York, New York; and Yale University School of Medicine, New Haven, Connecticut.

Disclaimer: All authors had access to the data, commented on drafts, and approved the final report. Dr. Naidoo had final responsibility for the decision to submit the report for publication.

Acknowledgment: The authors thank the patients for their participation in this study; Ms. Natasha Samsunder for laboratory analysis; Mrs. Anneke Grobler for statistical support; Ms. Tanuja Gengiah and Ms. Anushka Naidoo for pharmacy support; Professor Y.M. Moosa, Dr. Aarthi Singh, and Dr. Munira Khan for additional clinical support; Mr. Faldie Burton for data management; and all other members of the SAPiT study team.

Grant Support: The Centre for the AIDS Programme of Research in South Africa was established as part of the Comprehensive International Program of Research on AIDS (CIPRA) (grant AI51794) from the National Institutes of Health. The U.S. President's Emergency Plan for AIDS Relief funded the care of all of the participants in the trial. The Global Fund to Fight AIDS, Tuberculosis and Malaria funded the cost of the drugs used in the trial. The research infrastructure to conduct the trial, including the data management, laboratory, and pharmacy cores, was established through the CIPRA grant. Drs. Naidoo and Padayatchi were supported by the Columbia University-Southern Africa Fogarty AIDS International Training and Research Program, which is funded by 
the Fogarty International Center of the National Institutes of Health (grant D43TW00231).

Potential Conflicts of Interest: Disclosures can be viewed at www .acponline.org/authors/icmje/ConflictOfInterestForms.do?msNum=M12 -0437 .

Reproducible Research Statement: Study protocol: Available by contacting the authors. Statistical code and data set: Available from Ms. YendeZuma (e-mail, yende@ukzn.ac.za). Access to all items will be restricted (based on prior ethical approval for data use and on completion of written agreements with the author or research sponsor).

Requests for Single Reprints: Kogieleum Naidoo, MBChB, Doris Duke Medical Research Institute, 2nd Floor, University of KwaZuluNatal, 719 Umbilo Road, Private Bag X7, Congella, 4013, Durban, South Africa.

Current author addresses and author contributions are available at www .annals.org.

\section{References}

1. Fishman JE, Saraf-Lavi E, Narita M, Hollender ES, Ramsinghani R, Ashkin D. Pulmonary tuberculosis in AIDS patients: transient chest radiographic worsening after initiation of antiretroviral therapy. AJR Am J Roentgenol. 2000;174: 43-9. [PMID: 10628452]

2. Chien JW, Johnson JL. Paradoxical reactions in HIV and pulmonary TB. Chest. 1998;114:933-6. [PMID: 9743188]

3. Girardi E, Palmieri F, Cingolani A, Ammassari A, Petrosillo N, Gillini L, et al. Changing clinical presentation and survival in HIV-associated tuberculosis after highly active antiretroviral therapy. J Acquir Immune Defic Syndr. 2001; 26:326-31. [PMID: 11317073]

4. Piscitelli SC, Gallicano KD. Interactions among drugs for HIV and opportunistic infections. N Engl J Med. 2001;344:984-96. [PMID: 11274626]

5. Abdool-Karim SS, Abdool-Karim Q, Friedland G, Lalloo U, El-Sadr WM; START project. Implementing antiretroviral therapy in resource-constrained settings: opportunities and challenges in integrating HIV and tuberculosis care [Editorial]. AIDS. 2004;18:975-9. [PMID: 15096799]

6. French MA. HIV/AIDS: immune reconstitution inflammatory syndrome: a reappraisal. Clin Infect Dis. 2009;48:101-7. [PMID: 19025493]

7. Meintjes G, Lawn SD, Scano F, Maartens G, French MA, Worodria W, et al; International Network for the Study of HIV-associated IRIS. Tuberculosis-associated immune reconstitution inflammatory syndrome: case definitions for use in resource-limited settings. Lancet Infect Dis. 2008;8:516-23. [PMID: 18652998]

8. Elston JW, Thaker H. Immune reconstitution inflammatory syndrome. Int J STD AIDS. 2009;20:221-4. [PMID: 19304962]

9. World Health Organization. Global Tuberculosis Control: Epidemiology, Strategy, Financing. Geneva: World Health Organization; 2009.

10. Abdool Karim SS, Naidoo K, Grobler A, Padayatchi N, Baxter C, Gray A, et al. Timing of initiation of antiretroviral drugs during tuberculosis therapy. N Engl J Med. 2010;362:697-706. [PMID: 20181971]

11. Abdool Karim SS, Naidoo K, Grobler A, Padayatchi N, Baxter C, Gray AL, et al. Integration of antiretroviral therapy with tuberculosis treatment. N Engl J Med. 2011;365:1492-501. [PMID: 22010915]

12. Blanc FX, Sok T, Laureillard D, Borand L, Rekacewicz C, Nerrienet E, et al; CAMELIA (ANRS 1295-CIPRA KH001) Study Team. Earlier versus later start of antiretroviral therapy in HIV-infected adults with tuberculosis. N Engl J Med. 2011;365:1471-81. [PMID: 22010913]
13. Havlir DV, Kendall MA, Ive P, Kumwenda J, Swindells S, Qasba SS, et al; AIDS Clinical Trials Group Study A5221. Timing of antiretroviral therapy for HIV-1 infection and tuberculosis. N Engl J Med. 2011;365:1482-91. [PMID: 22010914]

14. Burman W, Weis S, Vernon A, Khan A, Benator D, Jones B, et al. Frequency, severity and duration of immune reconstitution events in HIV-related tuberculosis. Int J Tuberc Lung Dis. 2007;11:1282-9. [PMID: 18229435]

15. French MA, Lenzo N, John M, Mallal SA, McKinnon EJ, James IR, et al. Immune restoration disease after the treatment of immunodeficient HIV-infected patients with highly active antiretroviral therapy. HIV Med. 2000;1:107-15. [PMID: 11737333]

16. Murdoch DM, Venter WD, Feldman C, Van Rie A. Incidence and risk factors for the immune reconstitution inflammatory syndrome in HIV patients in South Africa: a prospective study. AIDS. 2008;22:601-10. [PMID: 18317001]

17. Ratnam I, Chiu C, Kandala NB, Easterbrook PJ. Incidence and risk factors for immune reconstitution inflammatory syndrome in an ethnically diverse HIV type 1-infected cohort. Clin Infect Dis. 2006;42:418-27. [PMID: 16392092]

18. Breton G, Duval X, Estellat C, Poaletti X, Bonnet D, Mvondo Mvondo D, et al. Determinants of immune reconstitution inflammatory syndrome in HIV type 1-infected patients with tuberculosis after initiation of antiretroviral therapy. Clin Infect Dis. 2004;39:1709-12. [PMID: 15578375]

19. Huruy K, Mulu A, Mengistu G, Shewa-Amare A, Akalu A, Kassu A, et al. Immune reconstitution inflammatory syndrome among HIV/AIDS patients during highly active antiretroviral therapy in Addis Ababa, Ethiopia. Jpn J Infect Dis. 2008;61:205-9. [PMID: 18503170]

20. Lawn SD, Myer L, Bekker LG, Wood R. Tuberculosis-associated immune reconstitution disease: incidence, risk factors and impact in an antiretroviral treatment service in South Africa. AIDS. 2007;21:335-41. [PMID: 17255740]

21. Shelburne SA, Visnegarwala F, Darcourt J, Graviss EA, Giordano TP, White AC Jr, et al. Incidence and risk factors for immune reconstitution inflammatory syndrome during highly active antiretroviral therapy. AIDS. 2005;19: 399-406. [PMID: 15750393]

22. Department of Health, Republic of South Africa. National Tuberculosis Management Guidelines 2008. Pretoria, South Africa: Department of Health, Republic of South Africa; 2008. Accessed at www.sasohn.org.za/images $/ 2010 \%$ 20Adult\%20ART\%20Guidelines.pdf on 12 July 2012.

23. Colebunders R, John L, Huyst V, Kambugu A, Scano F, Lynen L. Tuberculosis immune reconstitution inflammatory syndrome in countries with limited resources. Int J Tuberc Lung Dis. 2006;10:946-53. [PMID: 16964782]

24. Shelburne SA, Montes M, Hamill RJ. Immune reconstitution inflammatory syndrome: more answers, more questions. J Antimicrob Chemother. 2006;57: 167-70. [PMID: 16354748]

25. Lawn SD, Bekker LG, Miller RF. Immune reconstitution disease associated with mycobacterial infections in HIV-infected individuals receiving antiretrovirals. Lancet Infect Dis. 2005;5:361-73. [PMID: 15919622]

26. Narita M, Ashkin D, Hollender ES, Pitchenik AE. Paradoxical worsening of tuberculosis following antiretroviral therapy in patients with AIDS. Am J Respir Crit Care Med. 1998;158:157-61. [PMID: 9655723]

27. Navas E, Martín-Dávila P, Moreno L, Pintado V, Casado JL, Fortún J, et al. Paradoxical reactions of tuberculosis in patients with the acquired immunodeficiency syndrome who are treated with highly active antiretroviral therapy. Arch Intern Med. 2002;162:97-9. [PMID: 11784229]

28. Wendel KA, Alwood KS, Gachuhi R, Chaisson RE, Bishai WR, Sterling TR. Paradoxical worsening of tuberculosis in HIV-infected persons. Chest. 2001; 120:193-7. [PMID: 11451837]

29. Calligaro G, Meintjes G, Mendelson M. Pulmonary manifestations of the immune reconstitution inflammatory syndrome. Curr Opin Pulm Med. 2011; 17:180-8. [PMID: 21346572]

30. Meintjes G, Wilkinson RJ, Morroni C, Pepper DJ, Rebe K, Rangaka MX, et al. Randomized placebo-controlled trial of prednisone for paradoxical tuberculosis-associated immune reconstitution inflammatory syndrome. AIDS. 2010;24:2381-90. [PMID: 20808204] 


\section{Annals of Internal Medicine}

Current Author Addresses: Drs. Naidoo, Padayatchi, Nair, and Abdool Karim; Ms. Yende-Zuma; and Mr. Naidoo: Doris Duke Medical Research Institute, 2nd Floor, University of KwaZulu-Natal, 719 Umbilo Road, Private Bag X7, Congella, 4013, Durban, South Africa.

Dr. Jithoo: Postnet Suite 998, Private Bag X9, Benmore, 2010, Gauteng, South Africa.

Dr. Bamber and Ms. Gengiah: eThekwini Research Clinic, 3 Richards Road, Berea, 4000, Durban, South Africa.

Dr. El-Sadr: Mailman School of Public Health, Columbia University, 722 West 168th Street, Room 1312, New York, NY 10032.

Dr. Friedland: Yale University School of Medicine, 135 College Street, Suite 323, New Haven, CT 06510.

Author Contributions: Conception and design: Kogieleum Naidoo, N. Padayatchi, W.M. El-Sadr, G. Friedland, S. Abdool Karim.
Analysis and interpretation of the data: Kogieleum Naidoo, N. YendeZuma, N. Padayatchi, G. Friedland, S. Abdool Karim.

Drafting of the article: Kogieleum Naidoo, N. Yende-Zuma, Kasavan Naidoo, N. Jithoo, W.M. El-Sadr, S. Abdool Karim.

Critical revision of the article for important intellectual content: Kogieleum Naidoo, N. Yende-Zuma, N. Padayatchi, Kasavan Naidoo, N. Jithoo, S. Gengiah, W.M. El-Sadr, G. Friedland, S. Abdool Karim.

Final approval of the article: Kogieleum Naidoo, N. Padayatchi, W.M. El-Sadr, G. Friedland, S. Abdool Karim.

Provision of study materials or patients: Kogieleum Naidoo.

Statistical expertise: N. Yende-Zuma.

Obtaining of funding: S. Abdool Karim.

Administrative, technical, or logistic support: Kogieleum Naidoo, N. Padayatchi, N. Jithoo, S. Gengiah.

Collection and assembly of data: Kogieleum Naidoo, N. Yende-Zuma, Kasavan Naidoo, N. Jithoo, G. Nair, S. Bamber.

\section{Appendix Table 1. Patterns of Patient Withdrawal, by Study Group*}

\begin{tabular}{|c|c|c|c|}
\hline Study Duration & Early Integrated Treatment Group & Late Integrated Treatment Group & Sequential Treatment Group \\
\hline 0 to $<6 \mathrm{mo}$ & $\begin{array}{l}\text { Died }(n=7) \\
\text { Lost to follow-up }(n=13) \\
\text { Withdrawn ( } n=7) \\
\text { Requested withdrawal: } 1 \\
\text { Relocated: } 5 \\
\text { Could not attend visits: } 1\end{array}$ & $\begin{array}{l}\text { Died }(n=5) \\
\text { Lost to follow-up }(n=21) \\
\text { Withdrawn }(n=8) \\
\text { Requested withdrawal: } 5 \\
\text { Unable to adhere to protocol: } 1 \\
\text { Relocated: } 2\end{array}$ & $\begin{array}{l}\text { Died }(n=12) \\
\text { Lost to follow-up }(n=15) \\
\text { Withdrawn }(n=6) \\
\text { Requested withdrawal: } 1 \\
\text { Unable to adhere to protocol: } 1 \\
\text { Relocated: } 3 \\
\text { Receiving medications in other hospital: } 1\end{array}$ \\
\hline 6 to $<12 \mathrm{mo}$ & $\begin{array}{l}\text { Died }(n=2) \\
\text { Lost to follow-up }(n=2) \\
\text { Withdrawn }(n=3) \\
\text { Requested withdrawal: } 2 \\
\text { Relocated: } 1\end{array}$ & $\begin{array}{l}\text { Died }(n=6) \\
\text { Lost to follow-up }(n=8) \\
\text { Withdrawn }(n=7) \\
\text { Requested withdrawal: } 2 \\
\text { Unable to adhere to protocol: } 2 \\
\text { Relocated: } 3\end{array}$ & $\begin{array}{l}\text { Died }(n=19) \\
\text { Lost to follow-up }(n=12) \\
\text { Withdrawn }(n=5) \\
\text { Requested withdrawal: } 3 \\
\text { Unable to adhere to protocol: } 2\end{array}$ \\
\hline 12 to $18 \mathrm{mo}$ & $\begin{array}{l}\text { Died }(n=3) \\
\text { Lost to follow-up }(n=6) \\
\text { Withdrawn }(n=7) \\
\text { Requested withdrawal: } 5 \\
\text { Relocated: } 2\end{array}$ & $\begin{array}{l}\text { Died }(n=3) \\
\text { Lost to follow-up ( } n=4) \\
\text { Withdrawn }(n=7) \\
\text { Requested withdrawal: } 2 \\
\text { Unable to adhere to protocol: } 2 \\
\text { Relocated: } 3\end{array}$ & $\begin{array}{l}\text { Died }(n=2) \\
\text { Lost to follow-up }(n=7) \\
\text { Withdrawn }(n=6) \\
\text { Unable to adhere to protocol: } 5 \\
\text { Relocated: } 1\end{array}$ \\
\hline
\end{tabular}

* Deaths or withdrawals that happened after onset of IRIS have been removed so that the table matches Figure 3 . 


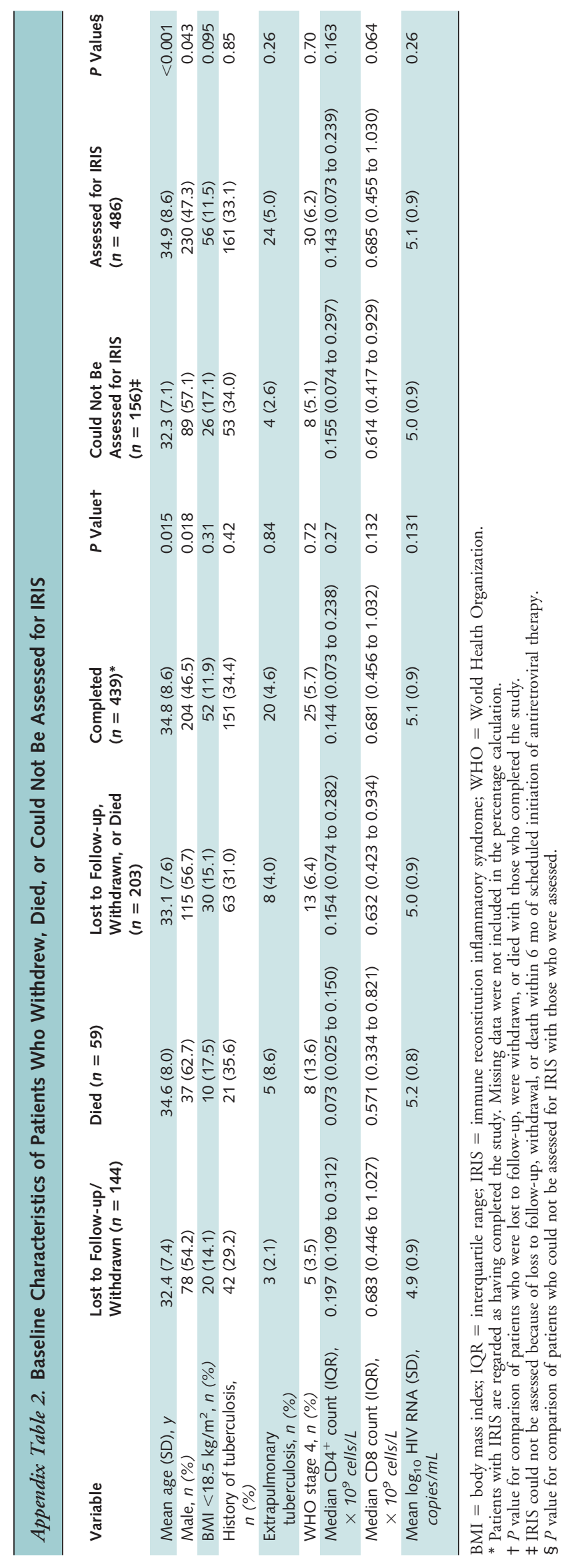

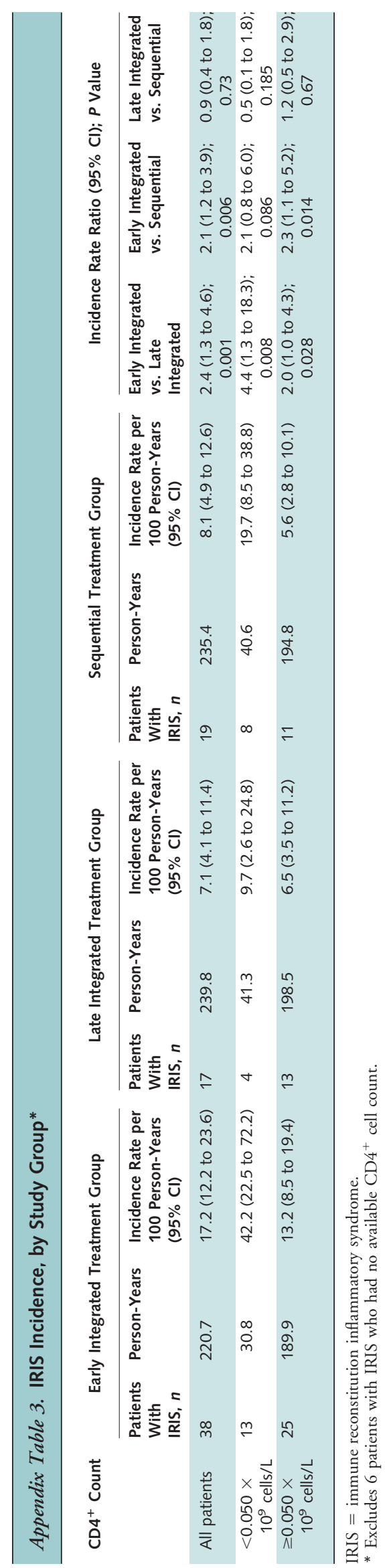

4 September $2012 \mid$ Annals of Internal Medicine $\mid$ Volume 157 • Number $5 \mid$ W-79

\section{Downloaded From: http://annals.org/ on 07/01/2013}




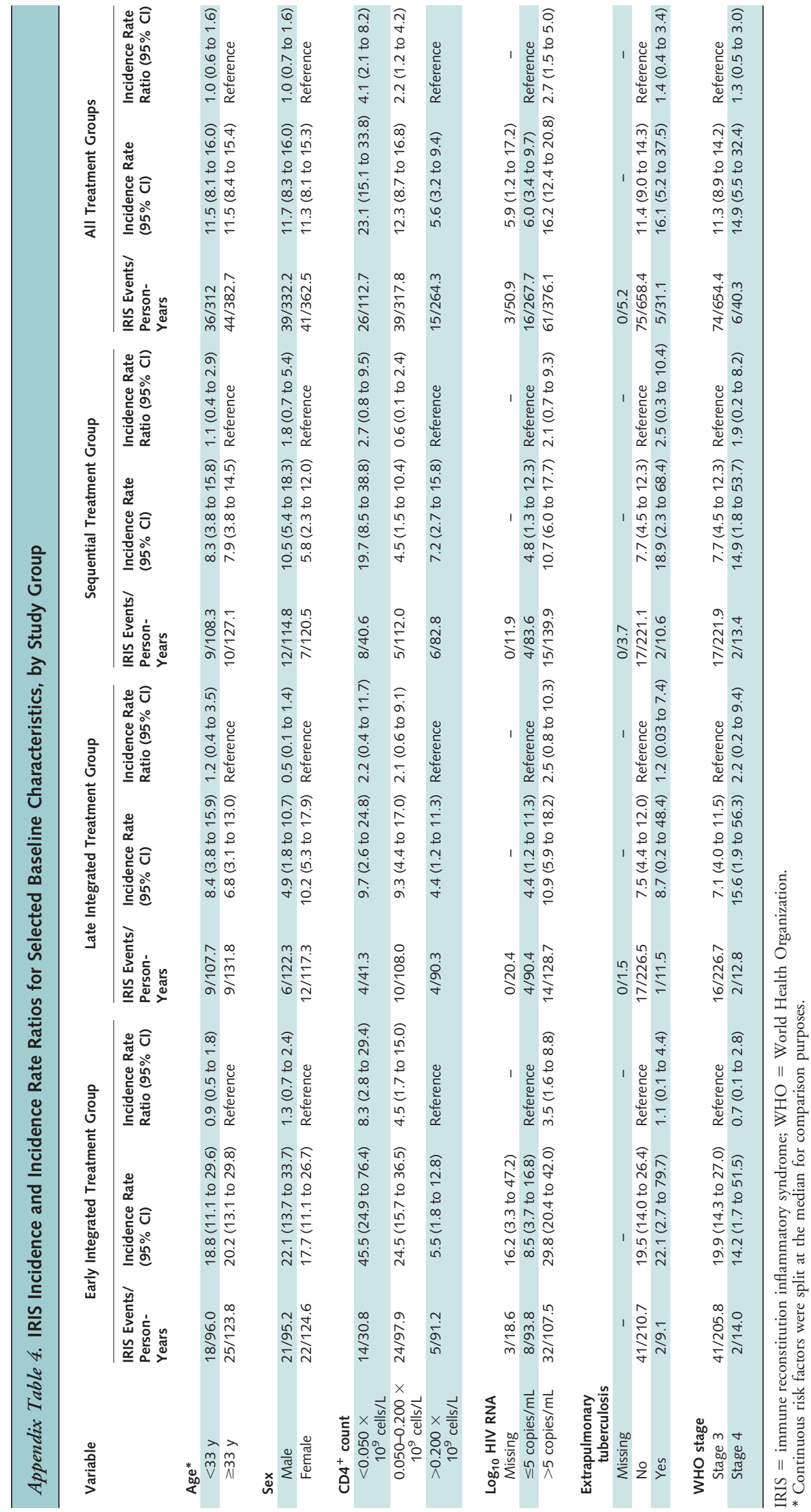

W-80 4 September 2012 $\mid$ Annals of Internal Medicine $\mid$ Volume 157 • Number 5 